\title{
1 Catalytic bitumen cracking in sub- and supercritical water
}

2 Xi-Kun Gai ${ }^{\mathrm{a}}$, Hiroyuki Arano ${ }^{\mathrm{b}}$, Peng Luª ${ }^{\mathrm{a}}$, Jian-Wei Mao ${ }^{\mathrm{a}}$, Yoshiharu Yoneyama ${ }^{\mathrm{b}}$, Cheng-Xue Lu ${ }^{\mathrm{a}}$,

3 Rui-Qin Yang ${ }^{\mathrm{a}^{*}}$, Noritatsu Tsubakia,b, **

$4 \quad{ }^{a}$ Zhejiang Provincial Key Lab for Chem. \& Bio. Processing Technology of Farm Product, School

5 of Biological and Chemical Engineering, Zhejiang University of Science and Technology, Hangzhou 310023, PR China

${ }^{b}$ Department of Applied Chemistry, Graduate School of Engineering, University of Toyama, Gofuku 3190, Toyama 9308555, Japan

9

\section{ABSTRACT}

The bitumen cracking reaction under sub- and supercritical water environments in $\mathrm{H}_{2}$ or $\mathrm{N}_{2}$ atmosphere using activated carbon (AC) supported nickel catalyst was studied. The sub- or supercritical water provided a unique homogeneous, acidic reaction system for the bitumen cracking reaction, which obviously promoted the bitumen conversion and selectivity of the middle distillates (kerosene and gasoline), and restrained the formation of carbon deposition, if compared with the conventional pyrolysis reaction without water addition. Moreover, the active in-situ $\mathrm{H}_{2}$ source was provided by the water-gas shift reaction in the sub- and supercritical water environment, thereby enhancing the catalytic activity of bitumen cracking.

Keywords: Bitumen; Cracking; Supercritical Water; Subcritical water; Ni/AC

* Corresponding author, Tel/Fax: +(86) -571-85070396;

E-mail address: yruiqin@163.com (R.Q. Yang);

** Corresponding author, Tel/Fax: +(81) -76-4456846;

E-mail address: tsubaki@eng.u-toyama.ac.jp (N. Tsubaki)

(C) 2015. This manuscript version is made available under the Elsevier user license http://www.elsevier.com/open-access/userlicense/1.0/ 


\section{Introduction}

Heavy oil such as oil sand bitumen, vacuum residue, asphalt and coal tar is an important energy resources because of its abundant supply [1,2]. The cracking of heavy oil is an essential process in petroleum industry, but it is difficult due to high impurity content of the heavy oil. In recent years, more attentions have been focused on the production of light hydrocarbons because of their wide application as synthetic middle distillates (kerosene and gasoline) [3-7]. A series of heavy oil cracking technologies have been developed during the past decade [8-9], such as fluid catalytic cracking process and hydrocracking, which can process various heavy oil to reach a high yield of middle distillates. Although these technologies are usually used to treat heavy oil, the consumption of expensive $\mathrm{H}_{2}$ is high in the cracking process. In order to overcome this disadvantage, the cracking of heavy oil under water environment is probably an alternative method for $\mathrm{H}_{2}$ supply. The physicochemical properties of supercritical water (critical point: $374{ }^{\circ} \mathrm{C}, 22.1 \mathrm{MPa}$ ), such as viscosity, diffusivity, dielectric constant, acidity and oxidizing property, are different significantly from those of conventional liquid water, which is also an effective solvent in a wide range of promising applications, such as biomass gasification, effluent treatment and heavy oil cracking [10].

Previous studies demonstrated that the utilization of water could promote the conversion of coal or cornstalk $[11,12]$. The hydrocarbons initially react with water to form $\mathrm{CO}$, subsequently the produced $\mathrm{CO}$ undergoes water-gas shift reaction (WGSR, $\mathrm{CO}+\mathrm{H}_{2} \mathrm{O} \rightarrow \mathrm{CO}_{2}+\mathrm{H}_{2}$ ) with supercritical water to generate in-situ $\mathrm{H}_{2}$, and finally proceeds to hydrocarbons hydrogenation and hydrocracking. Moreover, in-situ $\mathrm{H}_{2}$ is more active than the supplied one. Sato et al. reported an increase of asphaltene conversion through in-situ $\mathrm{H}_{2}$ [13]. The present paper investigated the cracking of Canadian Athabasca oil sand bitumen in sub- and supercritical water with $\mathrm{H}_{2}$ or $\mathrm{N}_{2}$ 
using the activated carbon (AC) supported Ni catalyst. The effects of sub- and supercritical water on bitumen conversion and the selectivity of middle distillates were discussed.

\section{Experimental}

Canadian Athabasca oil sand bitumen was selected as feedstock. Its component is listed in Table 1. The Ni loaded catalyst (5\% Ni/AC) was prepared by the incipient wetness impregnation method on AC with the aqueous solution of nickel nitrate. The AC was pretreated at $120{ }^{\circ} \mathrm{C}$ for $4 \mathrm{~h}$ in vacuum prior to impregnation. The wet catalyst was first dried at $120{ }^{\circ} \mathrm{C}$ in air for $10 \mathrm{~h}$, and then calcined in a ceramic tube furnace with flowing $\mathrm{N}_{2}$ at $400{ }^{\circ} \mathrm{C}$ for $2 \mathrm{~h}$, subsequently reduced with $\mathrm{H}_{2}$ at $400{ }^{\circ} \mathrm{C}$ for $10 \mathrm{~h}$ and then followed by passivation with $1 \% \mathrm{O}_{2}$ in $\mathrm{N}_{2}$. The bitumen cracking reaction was performed in a $20 \mathrm{~mL}$ batch autoclave reactor (HASTELLOY Alloy). The schematic diagram of experimental procedure and products analysis are showed in Fig. S1 and S2, respectively.

\section{Results and discussion}

\subsection{Comparison of bitumen cracking under water/without water environment}

As shown in Table 2, the selectivity of middle distillates is only $21.8 \%$ and $81.4 \%$ of bitumen conversion is reached for bitumen cracking reaction without water (Run 1). Additionally, the selectivities of naphtha, gaseous products and coke for this conventional pyrolysis reaction are $24.7 \%, 23.4 \%$ and $17.3 \%$, respectively. In contrast, the middle distillates selectivity and bitumen conversion are increased to $44.5 \%$ and $92.0 \%$ for bitumen cracking under supercritical water environment (Run 2), respectively. These results indicate that the bitumen cracking with supercritical water is more favorable to improve bitumen conversion and middle distillates selectivity since the supercritical water affords a unique homogeneous reaction environment. Coke 
formation is mainly derived from intermolecular reactions in bitumen [14]. The coke selectivity in Run 2 decreases appreciably due to the slowing down of the coking reaction by the mass-transfer resistance between different emulsion droplets in supercritical water [15].

\subsection{Investigation of bitumen cracking under sub-or supercritical water environment in $\mathrm{H}_{2}$}

For the bitumen cracking reaction in subcritical water, the selectivity of the middle distillates is as high as $59.7 \%$, which is higher than that of supercritical one (Run 2). Furthermore, the naphtha and coke selectivities also decrease due to lower reaction temperature of $350{ }^{\circ} \mathrm{C}$ in Run 3. Bitumen conversion is slightly decreased under subcritical water environment at $350{ }^{\circ} \mathrm{C}$ compared with Run 2 under supercritical water environment, even if the temperature of the latter is $50{ }^{\circ} \mathrm{C}$ higher. The reasons are attributed to the strong oxidizing property of supercritical water, leading to the fact that the active $\mathrm{Ni}^{0}$ sites of the $\mathrm{Ni} / \mathrm{AC}$ catalyst in Run 2 were oxidized and deactivated, as shown in XRD results (Fig. 1). In contrast, the subcritical water afforded a relatively mild environment for the bitumen cracking reaction. Therefore, although the temperature of Run 2 is higher, the bitumen conversion does not increase significantly if compared with that of Run 3.

\subsection{Influence of bitumen cracking atmosphere $\left(\mathrm{H}_{2}\right.$ or $\left.\mathrm{N}_{2}\right)$}

As listed in Table 2, the bitumen conversion is higher under $\mathrm{N}_{2}$ atmosphere than that under $\mathrm{H}_{2}$. The in-situ $\mathrm{H}_{2}$ is easily produced by WGSR of the produced CO with subcritical water for Run 4 under $\mathrm{N}_{2}$ atmosphere, whereas its formation is suppressed for Run 3 because of the present high pressure of $\mathrm{H}_{2}$. The active in-situ $\mathrm{H}_{2}$ promoted the bitumen cracking, leading to an enhanced bitumen conversion in Run 4. Surprisingly, the selectivity of gaseous products in Run 4 is only $0.1 \%$, which is significantly lower than that of Run 3. The selectivities of naphtha, kerosene and gasoline are similar between Runs 3 and 4, while Run 4 exhibits a higher VGO selectivity than that 
of Run 3, indicating that the coexisting high-pressure $\mathrm{H}_{2}$ results in a shift toward gaseous products. Therefore, subcritical water environment under $\mathrm{N}_{2}$ atmosphere is a better reaction condition for bitumen cracking than that under $\mathrm{H}_{2}$.

\subsection{Effect of sub-or supercritical water for bitumen cracking in $N_{2}$ atmosphere}

For Run 4, its bitumen conversion as high as $92.8 \%$, is similar to that under supercritical water condition (Run 5), whereas the naphtha and coke selectivities are lower in Run 4 but the selectivity of the middle distillates are higher. The selectivities of gaseous product, naphtha and kerosene increase when water state is changed by increasing the reaction temperature. Nevertheless, the gasoline selectivity decreases from $46.3 \%$ to $40.6 \%$ with an increasing reaction temperature, along with the decrease of VGO and residue selectivities. In fact, throughout the cracking of heavy oil, a parallel competition exists between decomposition and condensation [16]. The coke derives from the transformation of asphaltenes, while light fractions shift to heavy fractions. Not only coke selectivity increases from $5.8 \%$ to $8.8 \%$, but also the selectivity of middle distillates decreases from $59.6 \%$ to $57.1 \%$, since that the decomposition and condensation reactions are accelerated with increasing reaction temperature. Different from supercritical water, subcritical water acts as an organic solvent with high density, excellent solubility, providing milder temperature and pressure of bitumen cracking reaction than those in supercritical water environment. Therefore, under the similar catalytic activity and product distribution, the use of subcritical water remarkably reduces the cost of energy, pressure equipment, especially operational safety when compared with the cost of supercritical one. According to the above findings, the subcritical water environment at $350{ }^{\circ} \mathrm{C}$ and initial $\mathrm{N}_{2}$ atmosphere of 3.0 MPa can be regarded as the most suitable reaction conditions for the bitumen cracking reaction. 


\subsection{Gaseous products selectivities}

As Table 2 shows, the selectivity of total gaseous products obtained by conventional pyrolysis for Run 1 is markedly higher than those in other Runs 2-5 with sub- or supercritical water environment. The selectivity of total gaseous products is as high as $23.4 \%$, in which $\mathrm{H}_{2} \mathrm{~S}$, methane and ethane are main gases in the conventional pyrolysis (Table 3). However, the selectivity of total gaseous products in other reactions (Runs $2-5$ ) is less than $5 \%$. These results indicate that the gaseous products are restrained at higher pressure, which is in good agreement with the report of Bi et al. [17]. It can be observed that $\mathrm{H}_{2} \mathrm{~S}$ selectivity reaches $60.3 \%$ in the total gaseous products, whereas the total gas selectivity in all cracking products is the lowest for Run 4 under subcritical water and $\mathrm{N}_{2}$ atmosphere (Table 2). These findings prove that sub- and supercritical water can promote bitumen transformation to obtain middle distillates while suppressing the formation of gaseous products and coking.

\subsection{Hydrodesulfurization results}

The effect of sub- and supercritical water on the hydrodesulfurization of bitumen is compared with that of the conventional pyrolysis reaction, as shown in Table 4. After the reaction, the sulfur content in Run 1 with each fraction is lower than that of the additional water environment. Runs 2 to 5 show a trace amount of sulfur element in naphtha. The sulfur contents of kerosene, gasoline and VGO in Run 3 are lower than those of the supercritical one (Run 2), indicating that the hydrodesulfurization process was promoted under subcritical water condition. The sulfur contents in kerosene and gasoline under $\mathrm{H}_{2}$ atmosphere (Run 3) are higher than under $\mathrm{N}_{2}$ (Run 4). Nevertheless, the sulfur content in VGO is lower than that under $\mathrm{N}_{2}$. These results imply that the hydrodesulfurization process under $\mathrm{N}_{2}$ atmosphere was promoted to generate a low sulfur-containing of middle distillates under subcritical water condition. Therefore, subcritical water 
environment under $\mathrm{N}_{2}$ atmosphere is a better reaction condition for bitumen cracking than that under $\mathrm{H}_{2}$ atmosphere. For Run 5, the sulfur contents in distillates, including kerosene, gasoline and VGO, are higher than those of Run 4, implying that hydrodesulfurization process is promoted under subcritical water condition due to more reactive in-situ $\mathrm{H}_{2}$ formed through the WGSR.

\subsection{XRD analysis}

As Fig. 1 displays, the peaks at $37.3^{\circ}$ and $43.3^{\circ}$ are from the $\mathrm{NiO}$ phase, and the diffraction peaks of $44.3^{\circ}$ and $51.8^{\circ}$ are attributed to the $\mathrm{Ni}^{0}$ phase. The other peaks represent $\mathrm{Ni}_{3} \mathrm{~S}_{2}$. $\mathrm{The}^{\mathrm{Ni}}{ }^{0}$ diffraction peaks are observed from the reduced Ni/AC and spent catalysts in Runs 3 and 4 under subcritical water environment. Alternatively, the diffraction peaks of $\mathrm{NiO}$ are observed, which may be ascribed to the oxidation of $\mathrm{Ni}^{0}$ to $\mathrm{NiO}$ by supercritical water. In addition, $\mathrm{Ni}_{3} \mathrm{~S}_{2}$ is also deactivation and poisoning of catalysts because it is more difficult to remove in hydrodesulfurization process, even under supercritical water environment. All spent catalyst except Run 4, they display the strong $\mathrm{Ni}_{3} \mathrm{~S}_{2}$ crystal peaks, indicating that the partial $\mathrm{Ni}^{0}$ particles converted to $\mathrm{Ni}_{3} \mathrm{~S}_{2}$ after reaction.

\section{Conclusions}

The bitumen conversion and the selectivity of middle distillates under water environment were increased obviously if compared to those in the conventional pyrolysis reaction. Simultaneously, the selectivity of naphtha, gaseous products and coke decreased dramatically for the reaction with supercritical water environment and $\mathrm{H}_{2}$ at $400{ }^{\circ} \mathrm{C}$. Furthermore, the selectivity of the middle distillates increased, and the coke selectivity decreased for the reaction with subcritical water, compared to the reaction with supercritical water under $\mathrm{H}_{2}$ atmosphere. On the other hand, sub- and supercritical water with $\mathrm{N}_{2}$ provided an additional in-situ $\mathrm{H}_{2}$ source through WGSR, which was 
more active than the supplied $\mathrm{H}_{2}$ in the bitumen cracking reaction. The active in-situ $\mathrm{H}_{2}$ promoted bitumen cracking, thereby enhancing bitumen conversion, whereas the selectivity of gaseous products was decreased under the sub- or supercritical water environment accompanied by $\mathrm{N}_{2}$.

\section{Acknowledgements}

Financial aid from Japan Petroleum Energy Center (JPEC) is greatly appreciated. International research fund from JST-MOST project of China and Japan supports this research. Key Project for Science and Technology Innovation Team of Zhejiang Province (2011R09028) and Research Program for University Project Plan of Zhejiang Province (Y201120088) also support this research.

\section{References}

[1] K. Chao, Y.L. Chen, J. Li, X.M. Zhang, B.Y. Dong, Upgrading and visbreaking of super-heavy oil by catalytic aquathermolysis with aromatic sulfonic copper, Fuel Processing Technology 104 (2012) 174-180.

[2] D.L. Shi, X.Y. Wei, X. Fan, Z.M. Zong, B. Chen, Y.P. Zhao, Y.G. Wang, J.P. Cao, Characterizations of the extracts from geting bituminous coal by spectrometries, Energy \& Fuels 27 (2013) 3709-3717.

[3] J. Chang, K. Fujimoto, N. Tsubaki, Effect of initiative additives on hydro-thermal cracking of heavy oils and model compound, Energy \& Fuels 17 (2003) 457-461.

[4] J. Chang, N. Tsubaki, K. Fujimoto, M. Yoshimoto, Initiation effect of local heating in hydro-thermal cracking of resids, Energy \& Fuels 14 (2000) 1331-1332.

[5] J. Chang, Y. Fu, Y. Shibata, M. Yoshimoto, K. Fujimoto, N. Tsubaki, Promotional effect of oxidation pretreatment on hydro-thermal cracking of Canadian oil sand bitumen, Fuel 84 (2005) 1661-1663.

[6] L.A. Zhao, J.S. Gao, C.M. Xu, B.J. Shen, Alkali-treatment of ZSM-5 zeolites with different $\mathrm{SiO}_{2} / \mathrm{Al}_{2} \mathrm{O}_{3}$ ratios and light olefin production by heavy oil cracking, Fuel Processing Technology 92 (2011) 414-420.

[7] S.C. Qi, X.Y. Wei, Z.M. Zong, Y.K. Wang, Application of supported metallic catalysts in catalytic hydrogenation of arenes, RSC Advances 3 (2013) 14219-14232. 
[8] Y.S. Al-Degs, A. Ghrir, H. Khoury, G.M. Walker, M. Sunjuk, M.A. Al-Ghouti, Characterization and utilization of fly ash of heavy fuel oil generated in power stations, Fuel Processing Technology 123 (2014) 41-46.

[9] D. Rizwan, A.K. Dalai, J. Adjaye, Synthesis of novel polymer poly(glycidyl methacrylate) incorporated with tetranitrofluorenone for selective removal of neutral nitrogen species from bitumen-derived heavy gas oil, Fuel Processing Technology 106 (2013) 483-489.

[10] Y. Guo, S.Z. Wang, D.H. Xu, Y.M. Gong, H.H. Ma, X.Y. Tang, Review of catalytic supercritical water gasification for hydrogen production from biomass, Renewable \& Sustainable Energy Reviews 14 (2010) 334-343.

[11] Y. Yoneyama, S. Maekawa, A. Kanao, N. Tsubaki, Synergistic effect of pyrite and water on conversion of dibenzyl ether under coal hydrogenation conditions, Energy \& Fuels 17 (2003) 504-505.

[12] W.W. Zhu, Z.M. Zong, H.L. Yan, Y.P. Zhao, Y. Lu, X.Y. Wei, D.K. Zhang, Cornstalk liquefaction in methanol/water mixed solvents, Fuel Processing Technology 117 (2014) 1-7.

[13] T. Sato, T. Adschiri, K. Arai, G.L. Rempel, F.T.T. Ng, Upgrading of asphalt with and without partial oxidation in supercritical water, Fuel 82 (2003) 1231-1239.

[14] F. Bai, C.C. Zhu, Y. Liu, P.Q. Yuan, Z.M. Cheng, W.K. Yuan, Co-pyrolysis of residual oil and polyethylene in sub- and supercritical water, Fuel Processing Technology 106 (2013) 267-274.

[15] Z.M. Cheng, Y. Ding, L.Q. Zhao, P.Q. Yuan, W.K. Yuan, Effects of supercritical water in vacuum residue upgrading, Energy \& Fuels 23 (2009) 3178-3183.

[16] X.C. Tan, C.C. Zhu, Q.K. Liu, T.Y. Ma, P.Q. Yuan, Z.M. Cheng, W.K. Yuan, Co-pyrolysis of heavy oil and low density polyethylene in the presence of supercritical water: The suppression of coke formation, Fuel Processing Technology 118 (2014) 49-54.

[17] L.N. Han, R. Zhang, J.C. Bi, Upgrading of coal-tar pitch in supercritical water, Journal of Fuel Chemistry and Technology 36 (2008) 1-5. 
Graphical abstract

\section{Why use the supercritical water as medium?}

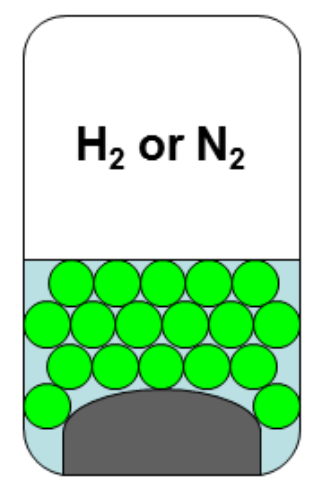

before reaction

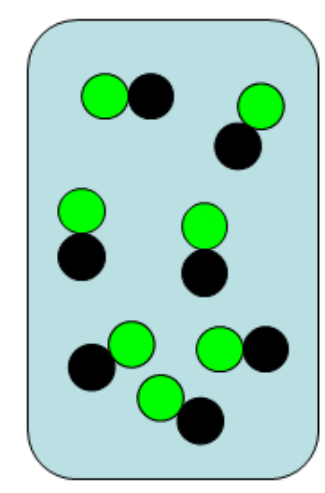

reacting

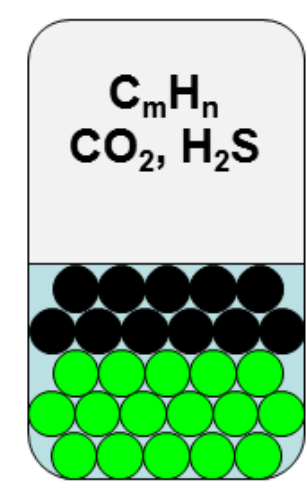

after reaction
$\mathrm{H}_{2} \mathrm{O}$
oil
bitumen

supercritical water

-374 ${ }^{\circ} \mathrm{C}, 22.1 \mathrm{MPa}$

-economic

- separation 


\section{Table 1}

Properties of Canadian Athabasca oil sand bitumen.

\begin{tabular}{|c|c|c|c|c|c|c|c|c|c|c|c|c|}
\hline \multirow{2}{*}{ API gravity } & \multirow{2}{*}{$\mathrm{CCR}^{\mathrm{a}}($ wt $\%)$} & \multicolumn{4}{|c|}{ Organic element content (wt\%) } & \multicolumn{2}{|c|}{ Metal content (ppm) } & \multicolumn{5}{|c|}{ Group composition (wt\%) } \\
\hline & & $\mathrm{C}$ & $\mathrm{H}$ & S & $\mathrm{N}$ & $\mathrm{Ni}$ & $\mathrm{V}$ & Saturate & Aromatics & Resin & Asphaltene & Residue \\
\hline 6.0 & 14.8 & 82.9 & 10.1 & 4.9 & 0.5 & 75 & 192 & 10.9 & 61.5 & 18.1 & 9.5 & 65.2 \\
\hline
\end{tabular}

${ }^{\text {a }}$ Conradson carbon residue. 
Table 2

Bitumen cracking in sub- or supercritical water.

\begin{tabular}{|c|c|c|c|c|c|c|c|c|c|c|c|c|c|c|}
\hline \multirow{2}{*}{ Run No. } & \multirow{2}{*}{$\begin{array}{l}\text { Atmo- } \\
\text { sphere }\end{array}$} & \multirow{2}{*}{$\begin{array}{l}\mathrm{T} \\
\left({ }^{\circ} \mathrm{C}\right)\end{array}$} & \multirow{2}{*}{$\begin{array}{l}\mathrm{H}_{2} \mathrm{O} \\
(\mathrm{g})\end{array}$} & \multicolumn{3}{|c|}{$\mathrm{P}(\mathrm{MPa})$} & \multirow{2}{*}{$\begin{array}{l}\text { Conv. } \\
(\%)\end{array}$} & \multicolumn{7}{|c|}{ Selectivity (wt\%) } \\
\hline & & & & Before & Reacting & After & & Gas & Naphtha & Kerosene & Gasoline & VGO & Residue & Coke \\
\hline 1 & $\mathrm{H}_{2}$ & 400 & & 3.0 & 8.6 & 3.3 & 81.4 & 23.4 & 24.7 & 10.4 & 11.4 & 0.70 & 12.1 & 17.3 \\
\hline 2 & $\mathrm{H}_{2}$ & 400 & 11 & 3.0 & 30.1 & 3.0 & 92.0 & 3.2 & 7.7 & 11.0 & 33.5 & 30.9 & 5.2 & 8.5 \\
\hline 3 & $\mathrm{H}_{2}$ & 350 & 11 & 3.0 & 17.3 & 3.0 & 86.0 & 4.6 & 3.8 & 13.3 & 46.4 & 18.6 & 9.1 & 4.2 \\
\hline 4 & $\mathrm{~N}_{2}$ & 350 & 11 & 3.0 & 17.9 & 3.0 & 92.8 & 0.1 & 3.5 & 13.3 & 46.3 & 26.3 & 4.7 & 5.8 \\
\hline 5 & $\mathrm{~N}_{2}$ & 400 & 11 & 3.0 & 30.1 & 3.1 & 97.7 & 1.0 & 9.0 & 16.5 & 40.6 & 22.6 & 1.5 & 8.8 \\
\hline
\end{tabular}


Table 3

Selectivity of gaseous products for the bitumen cracking.

\begin{tabular}{lllllllllll}
\hline \multirow{2}{*}{ Run No. } & \multicolumn{2}{l}{ Selectivity (wt\%) } \\
\cline { 2 - 11 } & $\mathrm{H}_{2} \mathrm{~S}$ & $\mathrm{CO}$ & $\mathrm{CH}_{4}$ & $\mathrm{C}_{2} \mathrm{H}_{6}$ & $\mathrm{C}_{2} \mathrm{H}_{4}$ & $\mathrm{C}_{3} \mathrm{H}_{8}$ & $\mathrm{C}_{3} \mathrm{H}_{6}$ & iso-- $4 \mathrm{H}_{10}$ & $\mathrm{C}_{4} \mathrm{H}_{10}$ & $\mathrm{C}_{4} \mathrm{H}_{8}$ \\
\hline 1 & 14.4 & 10.0 & 18.9 & 33.5 & 0.2 & 14.9 & 0.8 & 2.4 & 4.7 & 0.2 \\
2 & 15.6 & 80.6 & 2.4 & 0.4 & & 0.5 & 0.1 & 0.1 & 0.2 & 0.1 \\
3 & 4.9 & 66.6 & 9.5 & 7.8 & 0.3 & 5.9 & 0.7 & 1.0 & 2.9 & 0.4 \\
4 & 60.3 & & 14.5 & 7.5 & 1.2 & 8.3 & 2.9 & 1.2 & 3.5 & 0.6 \\
5 & 16.3 & & 31.6 & 17.3 & 1.8 & 17.4 & 4.3 & 2.6 & 6.8 & 1.9 \\
\hline
\end{tabular}

Reaction conditions: bitumen 2 g, 5\% Ni/AC 0.5 g, 1 h. 
Table 4

Elemental analysis of sulfur in distillates.

\begin{tabular}{lllll}
\hline \multirow{2}{*}{ Run No. } & \multicolumn{4}{l}{ S content (wt\%) } \\
\cline { 2 - 5 } & Naphtha & Kerosene & Gasoline & VGO \\
\hline 1 & 0.01 & 0.19 & 0.85 & 1.21 \\
2 & Trace & 0.42 & 1.36 & 1.67 \\
3 & Trace & 0.31 & 1.11 & 1.42 \\
4 & Trace & 0.25 & 0.96 & 1.85 \\
5 & Trace & 0.29 & 1.05 & 2.04 \\
\hline
\end{tabular}

Reaction conditions: bitumen 2 g, 5\% Ni/AC, 0.5 g, $1 \mathrm{~h}$; naphtha: IBP-170 ${ }^{\circ} \mathrm{C}$, kerosene: $170-230{ }^{\circ} \mathrm{C}$, gasoline: $230-343^{\circ} \mathrm{C}$, VGO (vacuum gasoline):

343-525 ${ }^{\circ} \mathrm{C}$, residue: $>525^{\circ} \mathrm{C}$. 


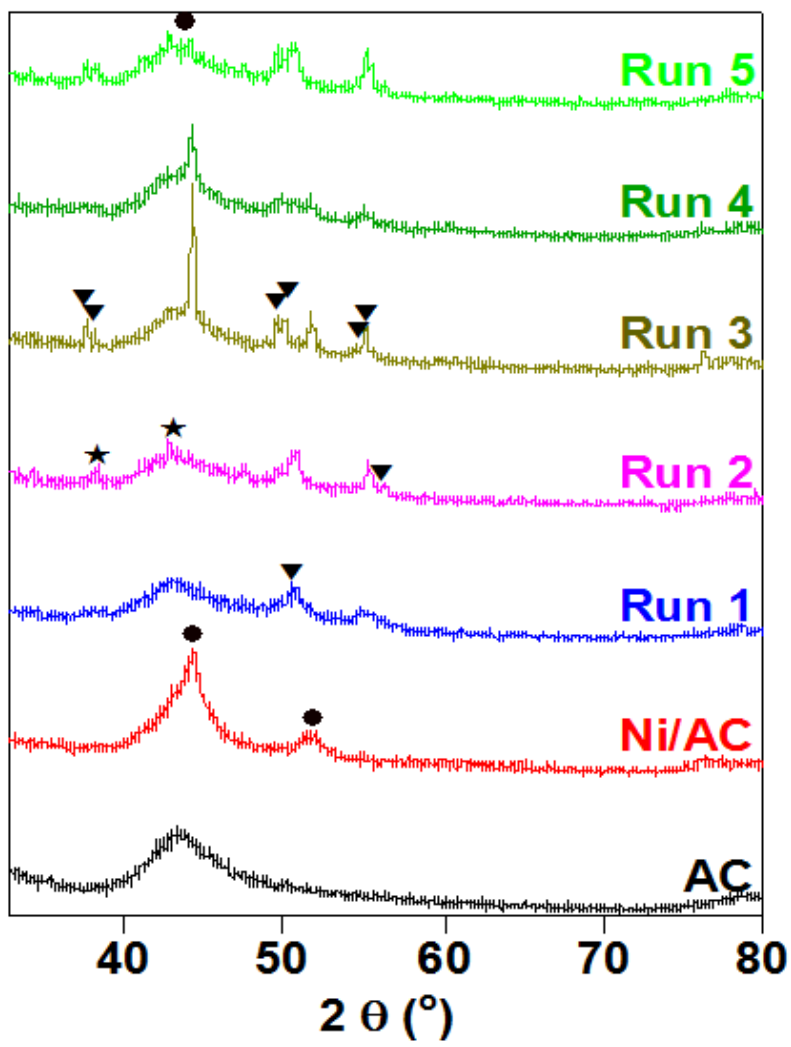

Fig. 1. XRD patterns of reduced fresh $\mathrm{Ni} / \mathrm{AC}$ and spent $\mathrm{Ni} / \mathrm{AC}$ catalysts under different reaction conditions $\left(\bullet \mathrm{Ni}^{0}, \star \mathrm{NiO}, \quad \nabla \mathrm{Ni}_{3} \mathrm{~S}_{2}\right)$. 